\title{
The Economic Impact of Arabica Coffee Farmers' Participation in Geographical Indication in Northern Highland of Thailand
}

\author{
Apichaya Lilavanichakul ${ }^{1) *}$
}

The use of geographical indication (GI) has been applied to many coffee farms aiming to link to origin and provide benefits and costs to the farmers and local community. This study examines the economic impact of GI for small-scale coffee farmers in Northern highland of Thailand. Propensity score matching (PSM) is used to estimate the comparison between GI and non-GI farmers on economic indicators: total cost, profit, and land productivity. Empirical result reveals that the number of off-farm family member and the distance from farm to a selling point increase the likelihood of GI participation. Another finding suggests that GI coffee farmers gain economic benefits from increasing profit and reducing the total cost, but lowering the land productivity. Thus, encouraging coffee farmers participating in GI scheme would improve economic benefits and boost farmer livelihoods in the specific geographical area.

Key words: economic impact, propensity score matching, Arabica coffee farming, geographical indication

\section{Introduction}

Arabica coffee is located in the Northern region of Thailand with the total production area of 19,900 ha (OAE, 2019). Thai Arabica coffee farming mainly located in the highland area where coffee beans originated in this area can develop a unique profile of acidity and flavors. Coffee farmers in the plateau area are local hill tribes (i.e. Ahka, Lisu, and Chinese Yunnan), which suffered from poverty and precarious livelihood conditions from illegal drug cultivation and burn agriculture in the past 50 years ago. The situation has changed in 1974 when the Royal Project for hill tribe development on Arabica coffee has been implemented. Nowadays, Arabica coffee has become a major source of income and improved better wellbeing for hill tribe communities.

The harvesting seasons for Thai Arabica coffee is during late October to February. Three selling channels of coffee cherries for Thai coffee farmers are the self-processing, the coffee plantation, and the intermediaries offering $20-30 \%$ price below the market price. Moreover, coffee farmers have faced unstable prices of coffee beans, lack of access to the market, and high production costs (i.e. hired labor, chemical fertilizers). To cope with these challenges, sustainable farming practices (i.e. geographical indication (GI) and organic) have been encouraged by the government to help Thai farmers to obtain premium prices and gain economic, environmental, and social benefits. Over the past 15 years, coffee farmer groups are increasingly interested in participating in Thai GI. Nevertheless, few attention has been studied on impact evaluation for implementing GI program to Thai coffee. To address whether Thai coffee farmers benefit from participating in GI or not, this paper evaluates the economic impact of GI for Thai Arabica coffee farmers.

\section{Geographical indication of coffee} (1) GI coffee in Thailand

The GI registration scheme has started since 2004 by the Department of Intellectual Property (DIP,

\footnotetext{
1) Department of Agro-Industrial Technology, Faculty of Agro-industry, Kasetsart University;

* E-mail: apichaya.1@ku.ac.th 


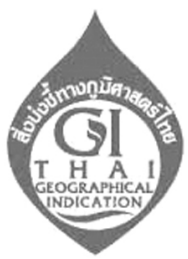

Fig. 1 Thai GI Symbol Source: DIP (2016)

2016). During the early period of GI adoption, the DIP selected high potential agricultural products related to geographical origin and registered GI. For example, two well-known Thai Arabica coffee, named Kafae Doi Tung and Kafae Doi Chaang, were financially supported and registered Thai GI by the DIP. For the GI registration scheme, local producers who are in the same specific geographical area must collaborate with related stakeholders and the local agricultural officers to identify the code of practice for a GI product which consists of a geographical name, qualities or characteristics, reputations related to origin, and a specific area on map. The certification of Thai GI must be renewed and paid a fee every two years. After the registered GI, the producers can place the Thai GI symbol on their GI products as illustrated in Figure 1. Self-control, internal control, and external control must be implied by collective actions to monitor the GI certification. GIs are recognized as valuable intellectual property and therefore offer both marketing tools (i.e. assuring the consumer trust, generating a premium on GI product) and protection of the geographical name.

According to the DIP database, there are seven certified GI coffees in Thailand. Each certified GI coffee must differ in a specific geographical origin and characteristics or process methods which are set out in the code of practice for GI. The coffee producers who produce GI coffee must fulfill the conditions of GI practices. The motivation to apply GI to Thai coffee is not only to differentiate the products with specific characteristics and geographical origin, but also to help the local development through premium prices and creating collective reputation for local community.

\section{(2) Studies on the impact of GI}

Previous studies on the impact of sustainable farming schemes (i.e. GI, fair-trade, and organic) on coffee have been studied on different aspects and economic levels (Angkasith, 2002; FAO, 2018). The treatment effect models have been used for analyzing the impact of fair-trade (Ruben and Fort, 2011), organic (Chiputwa et al., 2015), cooperatives (Mojo et al., 2017), shade coffee certification program (Takahashi and Todo, 2013). Some studies found that certified coffee farmers gain higher incomes than conventional coffee farmers, while a few studies revealed no significant economic impact on farmers. Sustainable coffee farming required key drivers including the use of fertilizers, the types of shade-tree, the water treatment, stakeholder engagement, and farmer networks (Pongvinyoo et al., 2014; Fatehah et al., 2019).

For the impact evaluation for GI, several studies focused on rural development (Jena et al., 2015), policy (Belletti et al., 2017), and farmer participation (Mojo et al., 2017). The impact of GI carried mixed effects on production costs and farmer welfare. To generate positive impacts and benefits to community, a collective reputation of GI played a significant role. Since GI is under a voluntary scheme, farmer participation in GI can be encouraged by the availability of information, credible certification system, local network, and economic improvement (Bramley, et al., 2009; Ngokkuen and Grote, 2012; Chiputwa et al., 2015).

\section{Methodology and data}

\section{(1) Propensity score matching (PSM)}

PSM refers to the pairing of the treatment variable and control variable with similar values on the propensity score (Rosenbaum and Rubin, 1983; Rubin, 2001). PSM is normally applied to evaluate impacts of a binary treatment variable and reduce the bias between groups. The estimation of the propensity 
Table 1. Description of explanatory variables

\begin{tabular}{lll}
\hline \hline \multicolumn{1}{c}{ Variable name } & & Description \\
\hline Off-farm family member & $x_{1}$ & Number of family members who work off the farm (persons) \\
Farming experience & $x_{2}$ & Number of years that a farmer has experiences on the farm (years) \\
Farm size & $x_{3}$ & The area of planting coffee (ha) \\
Distance & $x_{4}$ & The distance between farm and selling point (km) \\
GI Knowledge & $x_{5}$ & Value 1 if a farmer knows about GI application, 0 otherwise \\
Loan & $x_{6}$ & Value 1 if a farmer has loans, 0 otherwise \\
\hline
\end{tabular}

score is as follows:

$$
p(x)=\operatorname{Pr}_{i}[T=1 \mid x]=\mathrm{E}[T \mid x]
$$

where $p(x)$ is the predicted propensity score of farmer participating in GI. $T$ denotes a treatment variable, which is farmers participating in GI $(T=1)$. $x$ is a set of the covariates in Table 1 . To avoid an endogeneity problem leading to causal effect of GI participation on the outcome, all possible observable data that can be conducted in both treated and untreated groups are selected and used for the estimation of propensity score.

The average treatment effect (ATE) and the average treatment effect on the untreated (ATU) were estimated to compare difference between GI participation $(T=1)$ and non-GI participation $(T=0)$ on the economic outcomes, including the total cost, profit, and land productivity of coffee farmers. The ATE can be written as:

$$
A T E=\mathrm{E}\left[Y_{i}^{1}-Y_{i}^{0}\right]
$$

The ATU can be defined as:

$$
A T U=\mathrm{E}\left[Y_{i}^{1}-Y_{i}^{0} \mid T=0\right]
$$

where $Y_{i}^{1}$ is the economic outcome variable when $i$-th farmer participating in GI, and $Y_{i}^{0}$ is the economic outcome variable when $i$-th farmer not participating in GI. However, selection bias arises from the different characteristics between two groups. The PSM method is employed to mitigate a potential bias. The ATE can be presented as:

$$
A T E=\mathrm{E}\left[Y_{i}^{1} \mid T=1, p(x)\right]-\mathrm{E}\left[Y_{i}^{0} \mid T=0, p(x)\right]
$$

The ATU can be estimated as:

$$
A T U=\mathrm{E}\left[Y_{i}^{1} \mid T=0, p(x)\right]-\mathrm{E}\left[Y_{i}^{0} \mid T=0, p(x)\right]
$$

To implement PSM, the conditional independence assumption (CIA) must be satisfied where this refers to no confounding factors affecting the outcomes and the covariates. Thus, a randomized experiment is as follows:

$$
Y_{i}^{0}, Y_{i}^{1} \perp T \mid x
$$

Another assumption to employ PSM is the balancing property, which tests the balance of covariates after matching the treatment group and the control group. Moreover, the assumption of common support or covariate overlap is required that the conditional probability is satisfied the following condition; $0<p(x)=\operatorname{Pr}_{i}[T=1 \mid x]<1$.

Thus, the differences in the outcomes of GI and non-GI participation groups can be estimated (Caliendo and Kopeinig, 2008). Two matching techniques were selected for analysis: nearest neighbor matching (NNM) and kernel matching (KM). NNM is used to match the treated farmer with the nearest neighbors based on the propensity score distance. KM involves non-parametric approaches to match treated and control farmers in term of kernelweighted averages.

\section{(2) Data}

A plateau area located at Mae Suai district, Chiang Rai province in Northern part of Thailand was selected in this study. The total number of households in the survey area are about 1,000 households. The GI coffee program in the survey area has started since 2006. 
Coffee farmers who located in the certified GI area have a choice to participate in GI program or not to participate in GI program. The GI farmers must satisfy the standards set out in the code of practice for GI (i.e. using the particular Arabica species of coffee, cultivation practices, processing and roasting methods). For cultivation practices, the coffee trees must be grown between 1,100 to 1,700 meters above sea level and under a shade of trees (i.e. plum, peach, macadamia nut trees). Combinations of topography, organic soil matters, climate, and cultivation practices would develop unique characteristics on acidity, body texture, floral aroma, and fruity taste to the GI coffee. The harvesting method is the hand picking of only the ripe coffee cherries (red colour) and the ripe coffee cherries must be delivered to the selling channels on the same day. The farmgate price of GI coffee cherries was 22 THB per $\mathrm{kg}$, while the farmgate price of nonGI coffee cherries was unstable and ranged between 15-23 THB per kg. The farmers can sell the GI coffee cherries through the coffee manufacturers, local farmers, and the middlemen. The coffee cherries have been processed by the coffee manufacturer with specific processing and roasting methods set out in the code of practice for GI.
In-depth interviews with Arabica coffee experts on farming and a manager of coffee manufacturer were proceeded in order to develop the questionnaire. The complete sampling on the household survey in a single district were conducted during December 2016 to January 2017. The total size of 1,000 households were asked to response the questionnaire with the response rate of $10-15 \%$.

\section{Empirical results \\ (1) Coffee farmer profiles}

Total of 104 coffee farmers were conducted and descriptive statistics between farmers participating in GI (GI), and farmers not participating in GI (non-GI) were tested for mean differences as shown in Table 2. Both groups have similar family household, farming experience, small-scale farm size, land productivity, and distance to sell the coffee cherries. Since most coffee farmers in the highland area are hill tribes, the family size is quite large with the average of 6 persons per household. Moreover, the family households are likely to live close to their family relatives. Due to the rising prices of coffee, most hill tribe farmers have started coffee growing since 2002, giving both GI and non-GI groups have experiences on the coffee farming

Table 2. Descriptive statistics of coffee farmers' characteristics between $G I$ and non-GI

\begin{tabular}{lccccc}
\hline \multicolumn{1}{c}{ Characteristics } & GI $(n=66)$ & s.d. ${ }^{2}$ & Non-GI $(n=38)$ & s.d. ${ }^{2)}$ & $t$-value ${ }^{1)}$ \\
\hline Farmer characteristics & & & & & \\
\hline Family household (persons) & 5.742 & $(2.282)$ & 5.237 & $(2.211)$ & 1.10 \\
Off-farm family member (persons) & 1.697 & $(0.70)$ & 0.842 & $(1.15)$ & $4.711^{* * * *}$ \\
Farming experience (years) & 16.0 & $(7.467)$ & 14.711 & $(7.274)$ & 0.856 \\
Loan (dummy) & 0.606 & $(0.49)$ & 0.553 & $(0.50)$ & 0.528 \\
GI Knowledge (dummy) & 0.227 & $(0.42)$ & 0.211 & $(0.41)$ & 0.196 \\
\hline Farm characteristics & & & & \\
\hline Farm size (ha) & 3.678 & $(2.44)$ & 3.874 & $(3.32)$ & -0.345 \\
Land productivity (kg/ha) & $5,117.85$ & $(1968.52)$ & $5,150.58$ & $(1541.84)$ & -0.088 \\
Chemical fertilizer (kg/ha) & 857.32 & $(667.08)$ & $1,196.42$ & $(1506.02)$ & -1.583 \\
Weed control (dummy) & 0.197 & $(0.401)$ & 0.632 & $(0.489)$ & $-4.909^{* * * *}$ \\
Shade tree-macadamia (dummy) & 0.667 & $(0.48)$ & 0.289 & $(0.46)$ & $3.945^{* * * *}$ \\
Distance to sell coffee cherries (km) & 4.005 & $(2.36)$ & 5.108 & $(5.06)$ & -1.511 \\
\hline
\end{tabular}

$1) * * * * * *$ Significant at $1 \%$ level $(\mathrm{P}<0.01)$, at $5 \%$ level $(\mathrm{P}<0.05$, at $10 \%$ level $(\mathrm{P}<0.10)$, respectively.

2) s.d. stands for standard deviation. 
about $14-16$ years.

Unsurprisingly, GI knowledge of farmers were found no significant difference between GI and non-GI group. The GI registration has been processed by a leader of farmer group cooperating with the coffee manufacturers. Both of them have to communicate with farmers on GI farming practices and the standards set by the manufacturer, as well as offer supporting programs (i.e. a high farmgate price, job positions, and training) to provide incentive to farmers.

Findings showed that a few significant differences between GI and non-GI groups. GI group has larger off-farm family member and shade tree, while has lower weed control. For the number of off-farm family member, they tend to work at agricultural cooperatives, local government offices, and the coffee manufacturers. The fact that the leader of GI farmer group and the coffee manufacturer preferred to move toward sustainable farming. GI farmers were encouraged to plant coffee under the shade macadamia tree and use less herbicides to control weeds, even though these conditions do not identify in the GI practices. Note that the selection of shade tree on macadamia has been recommended by the agricultural research officers and local government (Angkasith, 2002). The results suggested that the treatment effects between GI and non-GI groups need to be considered.

\section{(2) Economic indicators}

The economic indicators between GI and non-GI groups were tested for mean differences as presented in Table 3. The mean of total cost was statistically significant differences between GI and non-GI groups. For the fixed cost, non-GI group has higher cost of investment on the farm than GI group, causing high opportunity costs and the amount of loan interest for non-GI group. The hired labor cost captured the largest proportion on variable cost for non-GI group, while the hired labor cost captured the second largest proportion on variable cost for GI group. Regarding to the in-depth interview with the leader of GI group, the GI farmers work with their network and operate the farm through collective action, leading to well manage the shift of hired labor, especially during the harvesting season where farmers face a shortage of

Table 3. Economic indicators of coffee farm

\begin{tabular}{|c|c|c|c|c|c|}
\hline Cost (THB/ha $)^{1)}$ & $G I^{2)}$ & s.d. ${ }^{3)}$ & Non-GI') & s.d. ${ }^{3)}$ & $t$-value $e^{4)}$ \\
\hline Variable cost & $24,065.47$ & (15081.79) & $33,538.42$ & (20257.48) & $-2.714^{* * *}$ \\
\hline Hired labor & $11,492.58$ & $(11094.22)$ & $17,584.92$ & (10187.99) & $-2.777^{* * *}$ \\
\hline Fertilizers and herbicides & $12,159.05$ & (9336.17) & $15,660.30$ & (15737.02) & -1.426 \\
\hline Fixed cost & $2,994.59$ & $(2212.42)$ & $3,792.93$ & (2018.25) & $-1.829 *$ \\
\hline Total cost & $27,060.06$ & (17166.07) & $37,331.35$ & $(21831.32)$ & $-2.656^{* * *}$ \\
\hline Gross farm income & $111,863.55$ & (43387.35) & $116,874.28$ & $(35486.86)$ & -0.605 \\
\hline Profit & $84,803.49$ & (40646.23) & $79,542.93$ & $(28883.71)$ & 0.702 \\
\hline
\end{tabular}

Source: Author's calculation.

1) Total cost $=$ Total variable cost + Total fixed cost; Gross farm income $=$ Total production $\times$ Farmgate price; Profit $=$ Gross farm income-Total cost. Note that total variable cost includes hired labor (i.e. spraying herbicides, transplanting, and trimming costs), fertilizers and herbicides, and other costs (i.e. transportation). The total cost does not include the registration fee for GI since the fee has been covered by the coffee manufacturer. Total fixed coat includes the depreciation of equipment, opportunity cost of investment on the farm, loan interest, and land tax where the depreciation of coffee trees and shade trees do not include in the fixed cost due to the limits of data on the depreciation of trees. Both GI and non-GI groups have started coffee cultivation in the same period, thus the depreciation of trees are assumed no difference between two groups.

2) Exchange rate: 1 US dollar (USD) $=30.40$ Thai Baht (THB) and 1 Japanese Yen (JPY) $=0.2821$ THB Source: Bank of Thailand (accessed on November 8, 2019).

3) s.d. stands for standard deviation.

4) $* * * * * *$ Significant at $10 \%$ level $(\mathrm{P}<0.10)$, at $5 \%$ level $(\mathrm{P}<0.05)$, at $1 \%$ level $(\mathrm{P}<0.01)$, respectively. 
Table 4. Logit model

\begin{tabular}{|c|c|c|c|c|}
\hline Variables & Coefficient & p-value ${ }^{1)}$ & $\begin{array}{l}\mathrm{BP}: \mathrm{NNM} \\
p \text {-value }\end{array}$ & $\begin{array}{l}\text { BP: KM } \\
\text { p-value }\end{array}$ \\
\hline Off-farm family member $x_{1}$ & $1.077 * * *$ & 0.000 & 0.357 & 0.405 \\
\hline Farming experience $x_{2}$ & 0.018 & 0.604 & 0.437 & 0.597 \\
\hline Farm size $x_{3}$ & -0.006 & 0.946 & 0.124 & 0.188 \\
\hline Distance $x_{4}$ & $-0.110^{*}$ & 0.095 & 0.250 & 0.288 \\
\hline GI Knowledge $x_{5}$ & -0.072 & 0.899 & 0.705 & 0.820 \\
\hline Loan $x_{6}$ & 0.246 & 0.605 & 0.496 & 0.477 \\
\hline Constant & -0.686 & 0.324 & & \\
\hline Pseudo $\mathrm{R}^{2}$ & & 0.172 & & \\
\hline Log likelihood & & -56.559 & & \\
\hline
\end{tabular}

$1) * * * * * *$ Significant at $1 \%$ level $(\mathrm{P}<0.01)$, at $5 \%$ level $(\mathrm{P}<0.05)$, at $10 \%$ level $(\mathrm{P}<0.10)$, respectively.

labor. In addition, GI group builds a strong relationship with the coffee manufacturer, so GI farmers receive some supports (i.e. sharing knowledge on farming practices, lowering the costs of fertilizers and herbicides, and providing free organic matter) from the manufacturer. This is different from non-GI group, which each farmer operates his/her farm separately and works in a small group. Moreover, non-GI group tends to heavily use hired labor to work on the farm, especially spraying herbicides and fertilizers.

\section{(3) Estimation of PSM}

The estimation result of logit model on the propensity score was shown in Table 4 . Overall, the estimated propensity score was significantly influenced by Off-farm family member $\left(x_{1}\right)$ and Distance $\left(x_{4}\right)$. The $R^{2}$ value at 0.172 indicated that the variation in the propensity can be performed by these significant covariates. A positive significant coefficient of Off-farm family member variable revealed that family members who work off the farm could provide incentives to farmers participating in GI. Off-farm family members may access GI information from their workplaces (i.e. local government offices and coffee manufacturers). Supportively, previous studies concluded that the socio-demographic characteristics of farmers (i.e. family member and farming experience) have an influence on farmer's decision (Bramley, et al., 2009; Fatehah et al., 2019). In addition, farmers facing a shortage of family member worked on the farm may be forced to look for alternative choices. The negative coefficient of Distance variable was significant, giving the shorter distance from farm to selling point (i.e. the coffee manufacturer), the more the likelihood of GI participation. Due to the coffee manufacturers are located close to coffee farming area, the social activities and interaction between farmers and the stakeholder are strongly developed. This suggests that potential networks (i.e. relatives, neighbors, and coworkers) and stakeholder engagement have prominent roles in the development of GI program.

Findings from the estimated treatment effect of three economic indicators between treated group (GI participation) and untreated group (non-GI participation) by the PSM model were presented in Table 5 . The assumption of balancing property (BP) of both NNM and KM are satisfied where the covariates are not different between the treated and untreated groups at significant $5 \%$ level as shown in Table 4 . The empirical results showed that the ATE and ATU values of three economic indicators under two matching techniques performed similar outcomes significantly. However, a small number of non-GI farmers pose too small observations to generate the counterfactual group and estimate the ATU. Unobserved variables like individual farming skills or ability and the relation with other farmers or 
Table 5. Estimates of the treatment effect between GI and non-GI groups

\begin{tabular}{lccccc}
\hline \hline & & \multicolumn{2}{c}{ Nearest neighbor matching (NNM) } & \multicolumn{2}{c}{ Kernel matching (KM) } \\
\cline { 3 - 6 } & & Difference (Treated-Untreated) & p-value & Difference (Treated-Untreated) & $p$-value \\
\hline Total cost & ATE & $-10,653.79^{* * *}$ & 0.004 & $-10,605.59^{* *}$ & 0.026 \\
\multirow{5}{*}{ Profit } & ATU & $-15,391.64^{* * *}$ & 0.009 & $-14,719.94^{* *}$ & 0.013 \\
& ATE & $12,176.44^{*}$ & 0.099 & $14,625.21^{*}$ & 0.068 \\
\multirow{3}{*}{ Land productivity } & ATU & $-3,433.84$ & 0.770 & $7,719.96$ & 0.543 \\
& ATE & $-656.25^{* *}$ & 0.016 & $-695.95^{* *}$ & 0.019 \\
& ATU & $-662.69^{* * *}$ & 0.001 & $-622.20^{* *}$ & 0.022 \\
\hline
\end{tabular}

1) ***,**,* Significant at $1 \%$ level $(\mathrm{P}<0.01)$, at $5 \%$ level $(\mathrm{P}<0.05)$, at $10 \%$ level $(\mathrm{P}<0.10)$, respectively.

stakeholders may bias the estimates of ATU. It is possible that the self-selection of selling channels by the non-GI farmers may lead to unstable farm income. Thus, the estimated ATE of the NNM method is selected for further discussion.

The negative ATE of land productivity $(-656.25$ $\mathrm{kg} / \mathrm{ha}$ ) interpreted that GI farmers have lower land productivity than non-GI farmers. This is as expected since GI farmers were encouraged to take account of reducing the use of herbicides and chemical fertilizers. Accordingly, the total cost for GI farmers is less than non-GI farmers (10,653.79 THB per ha) and the profit for GI farmers is greater than non-GI farmers $(12,176.44$ THB per ha). As a result, the significance of treatment effects suggest that GI program has a positive impact on economic benefits to Arabica coffee farmers in the surveyed area.

\section{Conclusions}

The GI scheme has been introduced to various agricultural products in Thailand to support local community and improve living standard of farmers. This paper focused on the economic impact evaluation of GI on coffee farmer's participation. Findings show a few significant differences between GI and non-GI farmers, thus the treatment effects by the PSM technique are suitable for the economic impact analysis. Another result indicates that the number of family members worked on the off-farm and the distance from coffee farms to the GI coffee manufacturer have an influence on convincing farmer's decision whether to participate in GI.

The empirical results of PSM model reveal significant difference on economic indicators between GI and non-GI groups. The GI farmers have lower total cost and higher profit than non-GI farmers, suggesting GI scheme on Arabica coffee has positively affected farmer's economic gain in the study area. To develop agricultural products related to specific geographical origin, GI scheme should be encouraged as a strategy to improve livelihood of small-scale farmers and local community. Moreover, the government should monitor the prices of input factors (i.e. fertilizers), as well as provide a proper training to build farmer's skills or ability and information on GI practices to farmers, thus they are able to apply the advantages of GI in different ways.

\section{Acknowledgments}

I am grateful to Kanyarat Totem who helped me to carry out the data collection.

\section{References}

Angkasith, P. (2002) Coffee production status and potential of organic Arabica coffee in Thailand, AU Journal of Technology 5(3). $\quad$ http://www.assumptionjournal.au.edu/index.php/ AUJournalofTechnology/article/view/1181/1060 (accessed on August 3, 2019).

Belletti, G., A. Marescotti, and J. M. Touzard (2017) Geographical indications, public goods, and sustainable development: The roles of actors' strategies and public policies, World 
Development 98: 45-57.

Bramley, C., E. Biénabe, and J. Kirsten (2009) The economics of geographical indications: towards a conceptual framework for geographical indication research in developing countries, The economics of intellectual property 109-149. https:// www.wipo.int/edocs/pubdocs/en/economics/1012/ wipo_pub_1012.pdf\#page=121 (accessed on August 3, 2019).

Caliendo, M. and S. Kopeinig (2008) Some practical guidance for the implementation of propensity score matching, Journal of Economic Surveys 22(1): 31-72.

Chiputwa, B., D. J. Spielman, and M. Qaim (2015) Food Standards, Certification, and Poverty among Coffee Farmers in Uganda, World Development 66: 400-412.

Department of intellectual property of Thailand (DIP) (2016) GI Thailand Volume 1 . https://www.ipthailand.go.th/th/ gi-014.html (accessed on August 3, 2019).

Fatehah, L., L. Apichaya, and P. Parthanadee (2019) An Analysis of Sustainability Indications on a Thai Arabica Coffee Value Chain, Panyapiwat Journal 11(1): 139-154.

Food and Agriculture Organization of the United Nations (FAO) (2018) Strengthening sustainable food systems through geographical indications: An analysis of economic impact, http://www.fao.org/3/a-i8737en.pdf (accessed on August 10, 2019).

Jena, P.R., C. Ngokkuen, D. B. Rahut, and U. Grote (2015) Geographical indication protection and rural livelihoods: insights from India and Thailand, Asian - Pacific Economic Literature 29(1): 174-185.

Mojo, D., C. Fischer, and T. Degefa (2017) The determinants and economic impacts of membership in coffee farmer cooperatives: recent evidence from rural Ethiopia, Journal of Rural Studies 50: 84-94.

Ngokkuen, C. and U. Grote (2012) Geographical indication for Jasmine Rice: applying a logit model to predict adoption behavior of Thai Farm Households, Quarterly Journal of International Agriculture 51(2): 157-185.

Office of Agricultural Economics (OAE) (2019) Agricultural Statistics of Thailand 2018. http://www.oae.go.th/assets/ portals/1/files/jounal/2562/yearbook2561.pdf (accessed on August 1, 2019).

Pongvinyoo, P., M. Yamao, and K. Hosono (2014) Factors affecting the implementation of good agricultural practices (GAP) among coffee farmers in Chumphon Province, Thailand, American Journal of Agricultural Development 2: 34-39.

Rosenbaum, P. R. and D. B. Rubin (1983) The central role of the propensity score in observational studies for causal effects, Biometrika 70(1): 41-55.

Rubin, D. B. (2001) Using propensity scores to help design observational studies: Application to the tobacco litigation, Health Services and Outcomes Research Methodology 2: 169188.

Ruben, R. and R. Fort (2011) The Impact of Fair Trade Certification for Coffee Farmers in Peru, World Development 40(3): 570-582.

Takahashi, R. and Y. Todo (2013) The impact of a shade coffee certification program on forest conservation: A case study from a wild coffee forest in Ethiopia, Journal of Environmental Management 130: 48-54. 